\title{
Bacterial Cellulose Membranes as a Potential Drug Delivery System for Photodynamic Therapy of Skin Cancer
}

\author{
Maristela F. S. Peres,,$^{a, \#}$ Karina Nigoghossian, ${ }^{b, \#}$ Fernando L. Primo, ${ }^{a, c}$ Sybele Saska, ${ }^{b}$ \\ Ticiana S. O. Capote, ${ }^{d}$ Raquel M. S. Caminaga, ${ }^{d}$ Younes Messaddeq, ${ }^{b}$ \\ Sidney J. L. Ribeiro ${ }^{b}$ and Antonio C. Tedesco ${ }^{*, a}$ \\ ${ }^{a}$ Centro de Nanotecnologia, Engenharia Tecidual e Fotoprocessos Voltado a Saúde, Grupo de \\ Fotobiologia e Fotomedicina, Departamento de Química, Faculdade de Filosofia, Ciências e Letras \\ de Ribeirão Preto (FFCLRP-DQ), Universidade de São Paulo, Campus Ribeirão Preto, \\ 14040-901 Ribeirão Preto-SP, Brazil

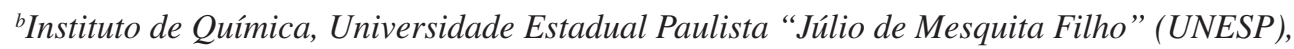 \\ CP 355, 14801-970 Araraquara-SP, Brazil \\ 'Departamento de Bioprocessos e Biotecnologia, Faculdade de Ciências Farmacêuticas, \\ Universidade Estadual Paulista "Júlio de Mesquita Filho" (UNESP), \\ 14801-902 Araraquara-SP, Brazil \\ ${ }^{d}$ Departamento de Morfologia, Faculdade de Odontologia, Universidade Estadual Paulista \\ "Júlio de Mesquita Filho" (UNESP), 14801-903 Araraquara-SP, Brazil
}

\begin{abstract}
The development of drug delivery systems for photodynamic therapy (PDT) is increasingly demanded due to the hydrophobicity presented by most of photosensitizers molecules. Bacterial cellulose (BC), a highly pure cellulose produced by bacteria, possesses the essential features for applications in drug delivery systems, such as large surface area and excellent loading capacity. BC membranes prepared containing a photosensitizer, chloroaluminum phthalocyanine (ClAlPc), were tested aiming applications as a drug delivery system for PDT skin cancer protocols. BC membranes production was optimized regarding thickness and optical transmission. Thinner membranes lead to higher relative incorporation efficiencies. Skin permeation and retention in vitro tests were performed by using pig's ears as a skin model. ClAlPc was retained at stratum corneum and epidermis/dermis, showing adequate properties for topical administration of ClAlPc. Photophysical studies showed that singlet oxygen production was not affected for ClAlPc compartmentalized in the $\mathrm{BC}$ array. BC-ClAlPc membranes did not present cytotoxic effects in vitro.
\end{abstract}

Keywords: bacterial cellulose, phthalocyanine, drug delivery system, photodynamic therapy

\section{Introduction}

A variety of new approaches and therapeutic protocols has been emerging in the last years as a consequence of the progresses in the field of applied nanobiotechnology to treat a huge spectrum of diseases, through improved targeting or delivery of the therapeutic agent. In the case of application for cancer therapeutics, these innovative technologies tend to be less invasive and more effective when compared with the most conventional antitumor treatment techniques:

*e-mail: atedesco@usp.br

"Maristela de F. S. Peres and Karina Nigoghossian contributed equally to this paper. surgery, radiotherapy and chemotherapy. ${ }^{1-3}$ Photodynamic therapy (PDT) has been focus of intense research during the last decades as an emerging therapeutic modality. Despite the fact of being a novel technique, PDT is a well-established procedure mainly used in the treatment of neoplastic and non-neoplastic diseases. ${ }^{4}$ This therapy is focused mainly in skin cancer treatment, from early stage until melanoma one (there is no indication for the use of this therapy to treat melanoma). PDT is already used as a clinical tool for treating tumors and a considerable number of pathological conditions, such as arthritis, skin disorders and many other non-oncological diseases. ${ }^{5-8}$ The technique is based on the injection, ingestion, or topical application of photosensitizer drugs (usually obtained from natural or 
synthetic sources, in the presence of a specific drug delivery system) followed by visible light activation. ${ }^{9}$ The classical photosensitizers are chemical compounds, which absorb visible light in a specific wavelength. Upon irradiation, the photosensitizer is promoted from its ground singlet state to its triplet excited state followed by reactions that occurs in a complex mechanistic pathway through classical photochemical reactions, ${ }^{10}$ leading to the production of reactive oxygen species (ROS), of which singlet oxygen is one of the main active species in photodynamic processes.

Most of the photosensitizers used in PDT present difficulty for administration in physiological environment due to their hydrophobicity. Therefore, it is necessary to develop drug delivery systems capable to overcome the tendency to aggregate in aqueous media. ${ }^{11}$ The development of new drug delivery systems based in nanobiotechnology has improved the therapeutic and toxicological properties of existing chemotherapeutic and photochemotherapeutic agents and fostered the implementation of new agents. A wide assortment of biomaterials with suitable biological properties is offered today as a potential tool to be used as a drug delivery system, but considerable attention has been drawn to the use of biocompatible polymers based ones. By combining drugs with different polymers, either synthetic or natural, it is possible to optimize pharmacokinetics and biodistribution of the agents, and, consequently efficacy and safety of therapy are improved. ${ }^{12}$ Additionally, the polymer offers protection against enzymatic, hydrolytic and other types of chemical degradation. ${ }^{13}$

Polymeric release systems can be designed in many forms, including matrices or membranes in which the active ingredient is dispersed or dissolved. ${ }^{14-16}$ The administration route, carrier formulation, release mechanism and physiochemical properties of drug molecule are determinant factors, which influence on drug release rate and thus must be considered when selecting a suitable polymer of a release device. ${ }^{17}$ Moreover, the ideal polymers for the development of dry delivery systems should be chemically inert to the drug action and present appropriate physical features. ${ }^{18}$

Bacterial cellulose (BC) is a polysaccharide of glucose produced by Gluconacetobacter sp. that is superior to plant cellulose due to its purity and nano-morphology. BC presents high water-holding capacity, large surface area, and high crystallinity, besides being renewable, biocompatible and biodegradable. ${ }^{19}$ The incorporation of organic/inorganic compounds in its structure is possible due to the network of ribbon-shaped nanosized cellulose fibrils and the high presence of water. A number of studies in the literature report the successful use of $\mathrm{BC}$ membranes in biomedical application $s^{20}$ and, more specifically, drug delivery systems ${ }^{21}$ due to their unique physical and mechanical properties. ${ }^{22}$ Such membranes are particularly advantageous in topical or transdermal drug delivery systems, as they have the ability to absorb exudates and adhere to irregular skin surfaces, such as the oral mucosa. ${ }^{23-26}$ Moreover, a previous study reported the good skin tolerance of BC membranes. ${ }^{27}$ As the majority of transdermal patches are manufactured by superimposing different materials, a system composed of fewer or even a single layer, such as a BC film, could simplify the preparation procedure and lower production costs..$^{28}$ Recently, our group has reported a system based on $\mathrm{BC}$ membranes incorporated with the photosensitizer chloroaluminum phthalocyanine (ClAlPc) and luminescent upconversion nanoparticles, which emits light at the wavelength range of ClAlPc absorption under infrared irradiation, within the biological transparency window. ${ }^{29}$ Chitosan, which is chemically related to cellulose and plant cellulose nanocrystals, has been studied by Schmitt et al..$^{30}$ and Drogat et al. $^{31}$ in photodynamic therapy. In view of these facts, the development of new delivery systems that can efficiently deliver ClAlPc could enable its clinical use for topical PDT.

The aim of the present study was to show the feasibility of bacterial cellulose as a potential drug delivery system for photodynamic therapy. The BC-ClAlPc membranes were evaluated regarding the incorporation efficiency of photosensitizer and in vitro diffusion studies with Franz cells. The BC-ClAlPc membranes were tested as a setup to activate photoprocesses useful for treat neoplastic and non-neoplastic diseases susceptible to the photoactivation process. The cytotoxicity potential of $\mathrm{BC}-\mathrm{ClAlPc}$ was evaluated aiming a safe use in humans.

\section{Experimental}

\section{Microorganisms}

The strains used were Acetobacter xylinum (ATCC 23760) and other isolated in the laboratory identified by Centro Pluridisciplinar de Pesquisas Químicas, Biológicas e Agrícolas (CPQBA), Universidade Estadual de Campinas (UNICAMP) as Gluconacetobacter sp. (GL). BC obtained from each microorganism were produced in two different stages of growth, in order to vary the thickness of the membranes: ATCC ( 2 and 3 days) and GL (1 and 3 days).

\section{Chemicals}

Glucose, yeast extract, potassium phosphate monobasic anhydrous, magnesium sulphate heptahydrate, and ethanol, all of analytical grade, were used for the 
microbiological culture media. ClAlPc, dimethyl sulfoxide (DMSO), phosphate buffer saline solution (PBS), sodium 3'-[1-(phenylaminocarbonyl)-3,4-tetrazolium]-bis (4-methoxy-6-nitro) benzene sulfonic acid hydrate (yellow tetrazolium salt XTT), cell culture medium Ham's F-10 (HAM-F10):Dulbecco's modified Eagle's (DMEN), 1:1 and doxorubicin were purchased from Sigma-Aldrich (St. Louis, MO, USA). Fetal bovine serum (FBS) and DMEM medium without phenol red were purchased from Cultilab (Campinas, SP, Brazil). XTT:electron solution 50:1 cell proliferation kit II (XTT) was acquired from Roche Molecular Biochemicals (Basel, Switzerland).

\section{Bacterial cellulose production}

The $\mathrm{BC}$ membranes were produced by growing the bacteria at $30{ }^{\circ} \mathrm{C}$ for $24 \mathrm{~h}$ in liquid medium under static conditions. Culture medium was composed of $50 \mathrm{~g} \mathrm{~L}^{-1}$ glucose, $4 \mathrm{~g} \mathrm{~L}^{-1}$ yeast extract, $2 \mathrm{~g} \mathrm{~L}^{-1}$ potassium phosphate monobasic anhydrous, $0.73 \mathrm{~g} \mathrm{~L}^{-1}$ magnesium sulphate heptahydrate, and $20 \mathrm{~g} \mathrm{~L}^{-1}$ ethanol. ${ }^{32}$ After this period, the flask was vigorously agitated and $10 \%$ of the culture media was withdrawn and inoculated into a new liquid production medium at $30^{\circ} \mathrm{C}$ over different periods of time (24, 48 and $72 \mathrm{~h})$.

\section{Bacterial cellulose purification}

After the incubation time, BC membranes were withdrawn from the culture medium and treated with a $0.1 \mathrm{~mol} \mathrm{~L}^{-1} \mathrm{NaOH}$ solution, at $80^{\circ} \mathrm{C}$, for $30 \mathrm{~min}$ to eliminate all attached cells. Then, the membranes were washed with distilled water to remove components of the culture media and other residues until its whitening and reaching $\mathrm{pH}$ 7.0. $\mathrm{BC}$ membranes were dried at $30^{\circ} \mathrm{C}$ and then stored in a desiccator. Measurements of the thickness of the membranes were performed in a Formtracer profilometer, model SV-CS25 (Mitutoyo, Kawasaki, Japan).

\section{Chloroaluminum phthalocyanine (CIAIPC) in bacterial cellulose membranes}

The $\mathrm{BC}$ wet membranes $(5 \times 5 \mathrm{~cm})$ were weighed. Moderate pressure was applied to the surface of the membranes to remove water until the mass loss of $50 \%$. The drained $\mathrm{BC}$ membranes were then soaked for $5 \mathrm{~h}$ in ClAlPc solutions in ethanol at concentrations of 1,5 and $10 \mu \mathrm{mol} \mathrm{L}{ }^{-1}$. The membranes were dried at $28{ }^{\circ} \mathrm{C}$ in a ventilated oven for $6 \mathrm{~h}$.

To facilitate the understanding of the results, it is important to highlight that $\mathrm{BC}$ refers to bacterial cellulose membranes and $\mathrm{BC}-\mathrm{ClAlPc}$ refers to the bacterial cellulose membranes incorporated with the photosensitizer ClAlPc. The samples are referred according to three factors: $(i)$ the strains from which membranes were produced: ATCC (A) or GL (G); (ii) the stages of growth: one, two or three days (1d, 2d and 3d, respectively); (iii) when applicable, the theoretical concentrations of ClAlPc $\left(1,5\right.$ and $\left.10 \mu \mathrm{mol} \mathrm{L}^{-1}\right)$ are indicated by the numbers 1,5 and 10 at the end of samples names. Table 1 presents the sample names according to these variables.

Table 1. List of sample names and corresponding variables

\begin{tabular}{lccc}
\hline Sample & Strain & $\begin{array}{c}\text { Stage of } \\
\text { growth / day }\end{array}$ & $\begin{array}{c}\text { Theoretical concentration } \\
\text { of ClAlPc } /\left(\mu \mathrm{mol} \mathrm{L}{ }^{-1}\right)\end{array}$ \\
\hline G1d1 & GL & 1 & 1 \\
A2d1 & ATCC & 2 & 1 \\
G3d1 & GL & 3 & 1 \\
A3d1 & ATCC & 3 & 1 \\
G1d5 & GL & 1 & 5 \\
A2d5 & ATCC & 2 & 5 \\
G1d10 & GL & 1 & 10 \\
A2d10 & ATCC & 2 & 10 \\
\hline
\end{tabular}

ATCC: Acetobacter xylinum; ClAlPc: chloroaluminum phthalocyanine; GL: Gluconacetobacter sp.

The quantification of ClAlPc was carried out according to a validated methodology based in fluorescence spectroscopic technique (Spex-FluoroLog 3, Horiba Jobin Yvon, Edison, NJ, USA) with excitation at fixed wavelength $\left(\lambda_{\mathrm{ex}} 615 \mathrm{~nm}\right)$ and emission at $680 \mathrm{~nm}$ (slits were adjusted to $10 \mathrm{~nm})^{33}$

The ClAlPc content was analyzed in two steps. Firstly, BC-ClAlPc $(1 \mathrm{mg})$ was immersed in $5 \mathrm{~mL}$ of acetonitrile at $60{ }^{\circ} \mathrm{C}$ for $15 \mathrm{~min}$ to determine the free ClAlPc content (non-incorporated drug). Subsequently, the membrane was immersed in $5 \mathrm{~mL}$ of acetonitrile and homogenized in an IKA Ultra-Turrax T-8 Basic (Staufen, Germany) at $11000 \mathrm{rpm}$ for $5 \mathrm{~min}$ to quantify ClAlPc retained into BC fibers. The concentrations were obtained from a calibration standard curve. Total ClAlPc concentration corresponds to the sum of the values found in sequential steps described above. Efficiency of incorporation (EI) of the photosensitizer into $\mathrm{BC}$ membranes was calculated by the following equation

$\mathrm{EI}(\%)=\left[\frac{(\text { total ClAlPc concentration }- \text { free ClAlPc concentration })}{\text { theoretical ClAlPc concentration }}\right] \times 100$

The experiments were performed in duplicate. One-way analysis of variance (ANOVA; OriginPro 8.0, OriginLab, 
Northampton, UK) was used for statistical analysis at a significance level $p<0.05$.

Scanning electron microscopy images of $\mathrm{BC}$ and BC-ClAlPc surfaces were obtained with a LEO equipment model 440 (Leica, Wetzlar, Germany) with an Oxford detector. Fourier transform infrared (FTIR) spectra were obtained with a PerkinElmer Spectrum 2000 Fourier transform infrared spectrophotometer (Waltham, MA, USA) using $\mathrm{KBr}$ pellets. Thirty-two scans were acquired over the range $4000-370 \mathrm{~cm}^{-1}$ with a resolution of $2 \mathrm{~cm}^{-1}$.

\section{In vitro skin diffusion studies}

PBS + ethanol $10 \%(\mathrm{v} / \mathrm{v} ; 7 \mathrm{~mL}, \mathrm{pH} 7.4)$ were used as the acceptor medium. ${ }^{34} \mathrm{~A}$ calibration standard curve of ClAlPc in the acceptor medium was constructed as a reference. Aliquots of ClAlPc were added with a microsyringe (Hamilton, Ocala, FL, USA) directly in medium in a $1.0 \mathrm{~cm}$ quartz cell under constant stirring. The fluorescence emission spectra were determined in the range of $0.219-1.314 \mu \mathrm{g} \mathrm{mL}-1(\mathrm{n}=10)$.

The skin was extracted from the dorsal surface of pig's ears, obtained directly from a slaughterhouse (Olho d'Água Ind. e Com. de Carnes Ltda., Ipuã, SP, Brazil), to be used as a model of skin. The front ear was dissected. The skins were applied in the tests in natura. These tissues were stored in a freezer up to a maximum of 90 days before their use in all in vitro procedures as an animal model. In vitro retention studies were carried out using the skin tissues fixed on Franz diffusion cells $\left(1.77 \mathrm{~cm}^{2}\right.$ diffusion surface areas) maintained at $37^{\circ} \mathrm{C}$ by a circulating water bath and stirring speed of $300 \mathrm{rpm}$. Samples were directly applied topically to the exposed area of skin. After 6,12 and $24 \mathrm{~h}$ of diffusion test, the system was dismounted and the skins were carefully removed to perform the tape-stripping analyses. In this second step, the stratum corneum (SC) was extracted from the diffusion surface by using 15 standardized stripping tapes (Scotch 3M, Maplewood, MN, USA). The tape-strips were placed in $5 \mathrm{~mL}$ of acetonitrile in glass tubes, stored overnight and then stirred for $1 \mathrm{~min}$ before filtration. The remaining skin (epidermis + dermis) was cut in small pieces and added to $5 \mathrm{~mL}$ of acetonitrile in a tissue homogenizer, sonicated for $20 \mathrm{~min}$ and then centrifuged for $15 \mathrm{~min}$ at $5000 \mathrm{rpm} .{ }^{35} \mathrm{ClAlPc}$ amounts present in tape-strips and remaining skin (epidermis + dermis) were assayed by fluorescence standard curve. Assays were performed in three independent experiments with five replicates on each. The statistical analysis was performed using the software OriginPro 8.0 (OriginLab, Northampton, UK) by the method one-way ANOVA at a significance level $p<0.05$.

\section{Photophysical studies}

Photophysical studies were performed to determine singlet oxygen generation. Lifetime was calculated from kinetic analysis of the mono-exponential decay for transient species obtained at $355 \mathrm{~nm}$. The spectrophotometer used for time-resolved measurements was an Edinburgh analytical instruments, model FL9000CD (Livingston, UK). The source of irradiation was a pulsed Nd:YAG laser from Continuum (Surelite I-10, Continuum, Santa Clara, CA, USA) adjusted for the third harmonic $(355 \mathrm{~nm})$. The pulse length was $8 \mathrm{~ns}$ and the repetition rate was $10 \mathrm{~Hz}$. The pulse energy was $15 \mathrm{~mJ}$, measured by a power meter (FieldMaster, Coherent, Santa Clara, CA, USA). The decay kinetics was measured at a single wavelength using a monochromator M300 and a photomultiplier R928P from Bentham Instruments (Livingston, UK). Singlet oxygen was detected by phosphorescence emission signal at $1270 \mathrm{~nm}$ using a germanium photodetector of North Coast Scientific Corporation, model 823 (North Coast Scientific, LLC., Santa Rosa, CA, USA). The software provided by Edinburgh instruments (L900, Livingston, UK) was used to obtain and analyze the exponential decay curves, based on iterative algorithm Marquadt (analysis of nonlinear least squares). The BC membrane produced by ATCC with theoretical ClAlPc concentration of $5.0 \mu \mathrm{mol} \mathrm{L}^{-1}$ was analyzed. ClAlPc in ethanol was adopted as a reference. The experiments were done using a solution of pheophorbide A in ethanol as a standard for relative calculations. ${ }^{36}$ The concentrations of reference solutions were adjusted based on the absorbance at $355 \mathrm{~nm}$ (excitation wavelength), fixed in 0.3 to avoid any internal filter effects. The measurements were performed under air-equilibrated conditions.

\section{Cytotoxicity test}

The potential cytotoxic effect of the new biomaterial obtained was evaluated by XTT assay that quantifies the cells by measuring their metabolic activity. The methodology is based on the cleavage of the yellow tetrazolium salt XTT by metabolically active cells, forming an orange formazan dye that can be measured by its absorbance at $492 \mathrm{~nm}$. Thus, this conversion occurs only in viable cells due to the activity of mitochondrial dehydrogenases. ${ }^{37}$

The BC-ClAlPc membranes were tested using an eluate prepared according to the ISO 10993-12:2007(E), considering the surface area $\left(6 \mathrm{~cm}^{2} \mathrm{~mL}^{-1}\right)$. The membranes were immersed in culture medium HAM-F10:DMEN 1:1 in the absence of FBS at $37{ }^{\circ} \mathrm{C}$ for $72 \mathrm{~h}$ under stirring $(133 \mathrm{rpm})$ in an incubator (New Brunswick Excella E24 incubator shaker, Edison, NJ, USA). After 72 h, the 
membranes were removed from the medium and this resulting eluate was used to carry out the treatment.

Chinese hamster ovary cells (CHO-K1) were cultured in the medium HAM-F10:DMEN 1:1 supplemented with $10 \%$ of $\mathrm{FBS}$ at $37^{\circ} \mathrm{C}$ and $5 \%$ of $\mathrm{CO}_{2}$. Cells were used after the third passage. Cytotoxicity test was performed in three independent replicates. Each treatment, including positive controls (PC) and negative controls (NC), was carried out in triplicate using cell culture plates.

Cells $\left(2 \times 10^{4}\right)$ were seeded in 24-well plates in culture medium (1 mL, HAM-F10:DMEN 1:1) supplemented with $10 \%$ of FBS at $37^{\circ} \mathrm{C}$ and $5 \%$ of $\mathrm{CO}_{2}$. After $24 \mathrm{~h}$, the cells were washed with PBS, and then treated with the eluates. The cells were exposed to the eluates for $24 \mathrm{~h}$. NC were cells CHO-K1 without any treatment (untreated controls), while PC were treated with doxorubicin $(3 \mu \mathrm{g} \mathrm{mL}-1)$ for $24 \mathrm{~h}$.

After the treatment, the cultures were washed with PBS $(250 \mu \mathrm{L})$ and inserted in the culture medium supplemented with FBS. After $24 \mathrm{~h}$ of incubation, the cells were washed with PBS $(250 \mu \mathrm{L})$. DMEM medium without phenol red was added $(1 \mathrm{~mL})$, followed by $60 \mu \mathrm{L}$ of XTT/electron solution 50:1 that remained in culture at $37^{\circ} \mathrm{C}$ for $3 \mathrm{~h}$. The culture medium was then transferred to a 96-well plate, and the absorbance was measured by a microplate reader (VersaMax, Molecular Devices, Sunnyvale, CA, USA) at 492 and $690 \mathrm{~nm}$. The absorbance is directly proportional to the number of viable cells in each treatment after $24 \mathrm{~h}$ of exposure.

For each analyzed sample, the results from three individual experiments (each one made in triplicate) were subjected to one-way ANOVA followed by Tukey's test. Dunnett's test was also applied to compare data from treated groups to the negative control. BioEstat statistical package version 5 was used (Universidade Federal do Pará, Belém, PA, Brazil) to perform the tests. Differences were considered statistically significant when $p<0.05$.

\section{Results and Discussion}

\section{Bacterial cellulose membranes characterization}

The bacterial cellulose membranes were obtained with different characteristics regarding thickness and transparency in accordance with the bacteria strain (ATCC or GL) and the growth time (1, 2 or 3 days). The thickness of pure bacterial cellulose membranes (Figure 1) were characterized by using a profilometer. One of the goals of this work was to produce BC membranes with different characteristics to select the most appropriate for the intended application. Thickness is a structural property of the membranes that influences loading and releasing efficiency of drug into the polymeric matrix. Note that the membranes produced by ATCC (with stage of growth of 2 and 3 days, A2d and A3d) present greater values of thickness $(103.2 \pm 6.9$ and $156.0 \pm 22.4 \mu \mathrm{m})$ due to a greater amount of cellulose fibers present. The membranes produced by the strain GL (with stage of growth of 1 and 3 days, G1d and G3d) are thinner (thickness of $39.7 \pm 5.3$ and $62.2 \pm 4.6 \mu \mathrm{m})$.

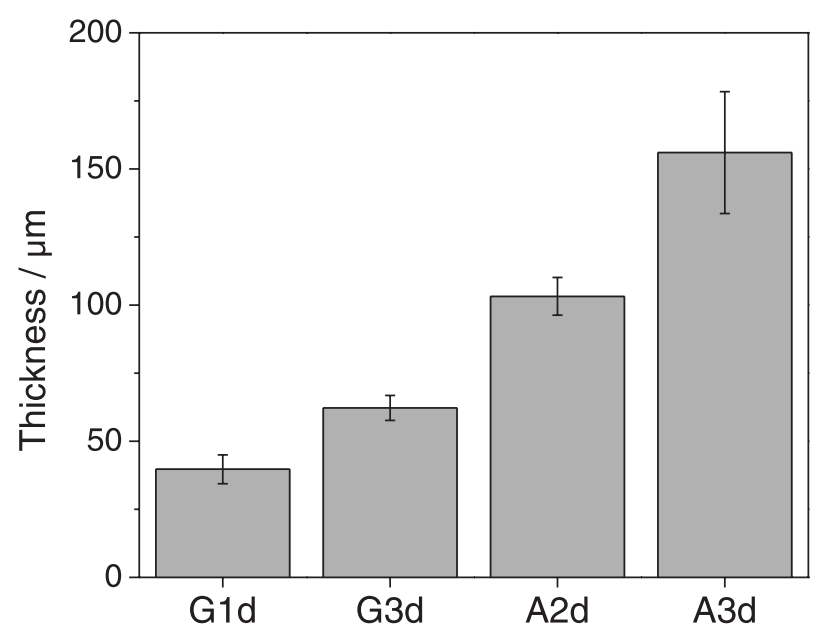

Figure 1. Thickness of pure bacterial cellulose (BC) membranes.

The electronic spectroscopy in the visible region was applied to evaluate the optical transmission of the membranes. Figure 2 shows the spectra of $\mathrm{BC}$ membranes, confirming the greater transparency at lesser thickness. We observed similar transparency for BCs produced by different strains. It is expected that a higher amount of fibers favors the incorporation of a greater amount of drug. The amount of fibers is improved with prolonged incubation of

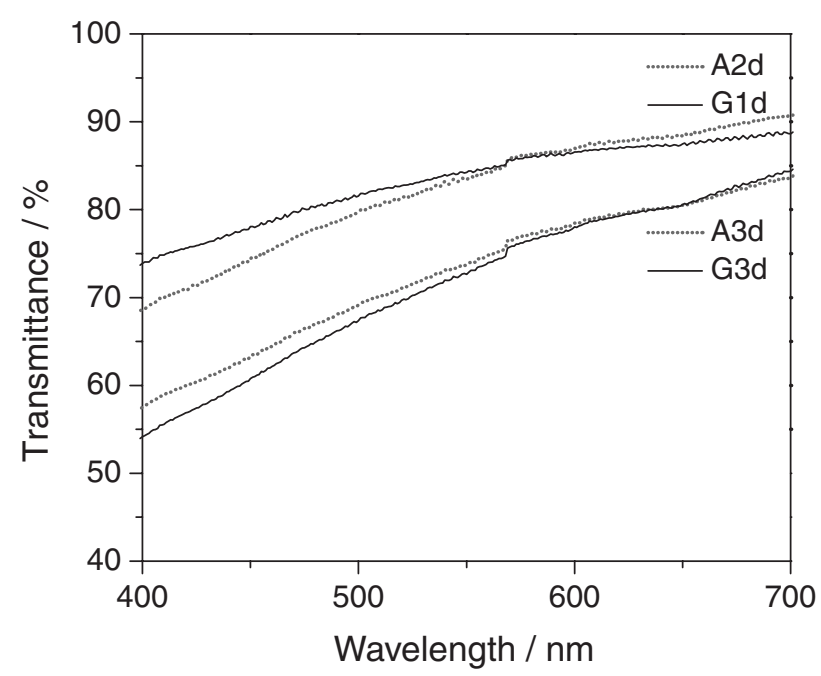

Figure 2. Optical transmission spectra of pure bacterial cellulose (BC) membranes. 
the bacteria. On the other hand, thicker membranes obtained from longer cultivation have lower transparency. The highly transparent media for incorporation of the photosensitizer is favorable for the transmission of the source of light used for excitation.

\section{CIAIPc incorporation in bacterial cellulose membranes}

The strategy used here was the incorporation of ClAlPc into the bacterial cellulose membrane, for use in PDT trials for cancer treatment. The pure $\mathrm{BC}$ wet membrane (Figure 3a) was soaked in a solution of ClAlPc (Figure 3b) and then dried (Figure 3c). The color of the membranes turned from white to blue after incorporation of ClAlPc. The morphology was investigated by scanning electron microscope (SEM) as shown in Figure 3d. The micrographs of BC-ClAlPc showed the tridimensional fibrillar network characteristic of $\mathrm{BC}$ and the absence of aggregates formation, which indicated no precipitation of ClAlPc.

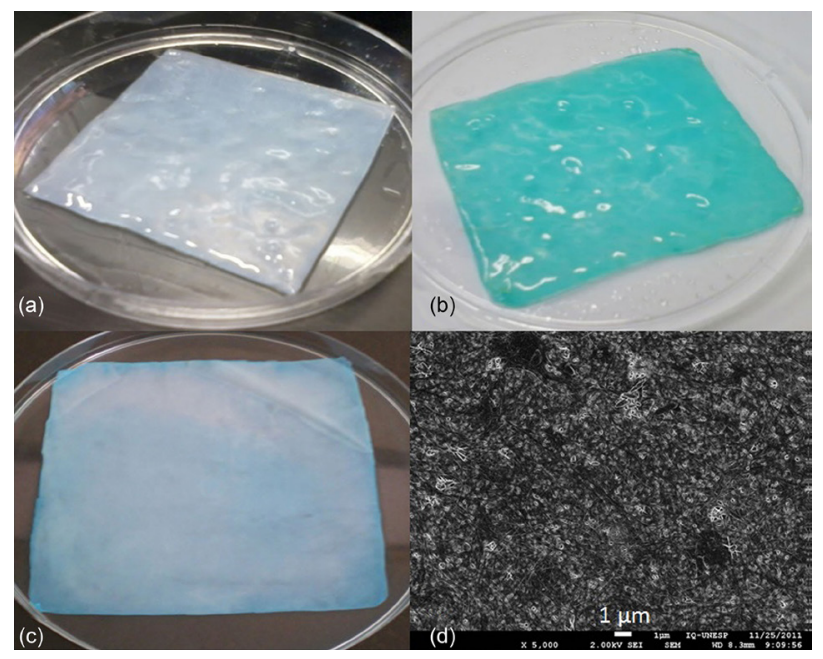

Figure 3. Photographs of pure bacterial cellulose (BC) wet membrane (a); BC- chloroaluminum phthalocyanine (ClAlPc) wet (b); dried BCClAlPc membrane (c); and scanning electron microscope (SEM) image of BC-ClAlPc (d).

Figure 4 displays the FTIR spectra of ClAlPc, pure $\mathrm{BC}$ dried membrane and BC-ClAlPc. The characteristic vibrational frequencies assigned to cellulose were observed at 3500 to $3200 \mathrm{~cm}^{-1}$ (OH stretching), $2908 \mathrm{~cm}^{-1}$ (CH stretching of $\mathrm{CH}_{2}$ and $\mathrm{CH}_{3}$ groups), $2700 \mathrm{~cm}^{-1}$ $\left(\mathrm{CH}_{2}\right), 1645 \mathrm{~cm}^{-1}$ (water $\mathrm{OH}$ bending), $1435 \mathrm{~cm}^{-1}\left(\mathrm{CH}_{2}\right.$ symmetric bending), $1370 \mathrm{~cm}^{-1}$ (CH bending), $1160 \mathrm{~cm}^{-1}$ (anti-symmetric bridge C-O-C stretching), 1111 and $1056 \mathrm{~cm}^{-1}$ (skeletal vibrations involving C-O stretching). ${ }^{19}$ The phthalocyanines present the following characteristic bands: at around 518 and $760 \mathrm{~cm}^{-1}$ (Al-N stretching), $1329 \mathrm{~cm}^{-1}$ (C-N-C stretching), $1121 \mathrm{~cm}^{-1}(\mathrm{C}=\mathrm{C}$ stretching of benzene rings) and $489 \mathrm{~cm}^{-1}$ (stretching $\mathrm{Cl}-\mathrm{Al}$ ). ${ }^{38}$ The spectrum of BC-ClAlPc is basically formed by the sum of the bands present in the BC and ClAlPc spectra. The decrease in intensity of the band with a peak at $2908 \mathrm{~cm}^{-1}$ (CH stretching of $\mathrm{CH}_{2}$ and $\mathrm{CH}_{3}$ groups) on BC-ClAlPc spectrum suggests that the presence of the ClAlPc affected the cellulose groups, due to the interactions between the hydrophobic ClAlPc molecule and $\mathrm{CH}$ groups of cellulose, and confirms the strong interaction between the $\mathrm{BC}$ and ClAlPc.

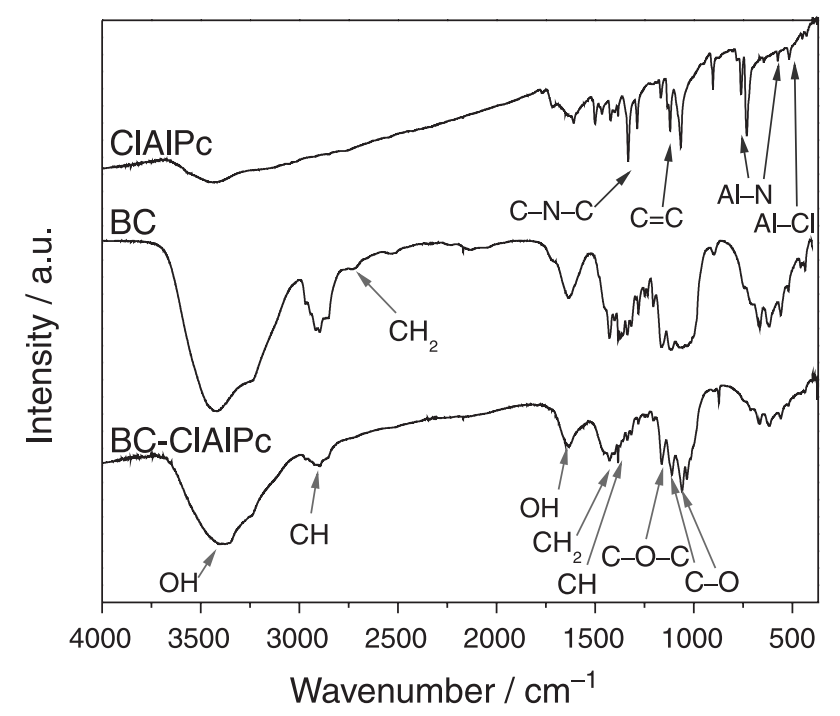

Figure 4. Fourier transform infrared (FTIR) spectra of chloroaluminum phthalocyanine (ClAlPc), dried bacterial cellulose (BC) membrane and BC-ClAlPc membrane.

The incorporation efficiency of ClAlPc from the solutions of different concentrations into membranes with different characteristics was studied. Fluorescence spectra (excitation at $615 \mathrm{~nm}$ ) were measured after the steps of extraction of free ClAIPc in acetonitrile and homogenization of BC membranes. The ClAlPc well known emission at $680 \mathrm{~nm}$, obtained under $615 \mathrm{~nm}$ excitation, is shown in the Figure 5a. The presence of the characteristic emission of ClAlPc confirmed the incorporation of this phthalocyanine derivative into BC fibrils. ${ }^{33,39}$

Figure $5 \mathrm{~b}$ shows the ClAlPc amount retained in the fibrils (measured at homogenization step) and total ClAlPc for membranes with different theoretical concentrations $\left(1,5\right.$ and $\left.10 \mu \mathrm{mol} \mathrm{L}^{-1}\right)$. These membranes were produced with the minimal time of growth stage that was enough to obtain membranes with satisfactory mechanical resistance and good transparency (that is 1 day for GL and 2 days for ATCC). The incorporation efficiencies of ClAlPc are listed in Table 2. The statistical analysis (ANOVA) confirmed a significant difference $(p>0.05)$ between the membranes. It was possible to determine an efficient and 
validate quantification method for analyses of ClAlPc loaded into cellulose. ${ }^{33}$ Studies have investigated the incorporation efficiency of ClAlPc in different bacterial cellulose membranes. A2d showed higher concentrations in steps of extraction and homogenization for all theoretical concentrations studied $\left(1,5\right.$ and $\left.10 \mu \mathrm{mol} \mathrm{L}^{-1}\right)$. Figure $5 \mathrm{~b}$ shows that, as the theoretical concentration of ClAlPc increases, the amount of ClAIPc retained in the cellulose fibers increases in a less pronounced way in respect to the total amount of incorporated drug (free + retained). Thus, membranes with lower ClAlPc theoretical concentration retain the drug more efficiently.

Table 2. Percentage of chloroaluminum phthalocyanine (ClAlPc) incorporated into the cellulose

\begin{tabular}{lc}
\hline Sample & Incorporation / \% \\
\hline G1d1 & $47.5 \pm 6.7$ \\
A2d1 & $87.4 \pm 3.4$ \\
G3d1 & $44.6 \pm 8.6$ \\
A3d1 & $41.7 \pm 31.9$ \\
G1d5 & $25.7 \pm 17.3$ \\
A2d5 & $41.8 \pm 8.0$ \\
G1d10 & $27.1 \pm 2.8$ \\
A2d10 & $34.0 \pm 3.2$ \\
\hline
\end{tabular}

As expected, A2d1 showed the highest incorporation efficiency (87.4\%; Table 2). The membranes grown for shorter time (A2d and G1d) have higher incorporation efficiency than A3d and G3d, and therefore they were selected for the skin permeation and retention tests. The structural characteristics of the three-dimensional network formed by cellulose nanofibrils, such as fiber density and surface area, influence on the interaction between drug molecule and polymeric matrix. Such properties influence on drug incorporation efficiency and release kinetics according to each biomaterial obtained and may be adjusted by varying the $\mathrm{BC}$ production process parameters. The higher amount of drug incorporated by thinner membranes (A2d and G1d) can be related to its larger surface area. In addition to this fact, a greater amount of cellulose fibers is another feature that favors higher concentrations, as observed for the membrane A2d..$^{40}$

\section{Skin permeation and retention in vitro studies}

For in vitro permeation and skin retention, it was necessary to develop a standard calibration curve to quantify the ClAlPc present in the environment of the receiver solution (PBS pH 7.4, and ethanol 10\% v/v). Serial dilutions were made with known concentrations of ClAlPc and the emission spectra were obtained under the same conditions. The curves were plotted from the emission intensities at $680 \mathrm{~nm}$ as a function of ClAlPc concentration. Five curves were obtained with high coefficients of determination $\left(\mathrm{R}^{2}\right)$, greater than 0.99 . The calibration standard curve was obtained $\left(\mathrm{y}=310357 \mathrm{x}+218237, \mathrm{R}^{2}=0.99\right)$ in the concentration range from 0.219 to $1.314 \mu \mathrm{g} \mathrm{mL}^{-1}$.

In studies using Franz cells, the permeation profile is drawn from the quantification of ClAlPc present in the receiver solution. The tests performed for $\mathrm{BC}$ membranes G1d1 and A2d1 and control test (without the bacterial
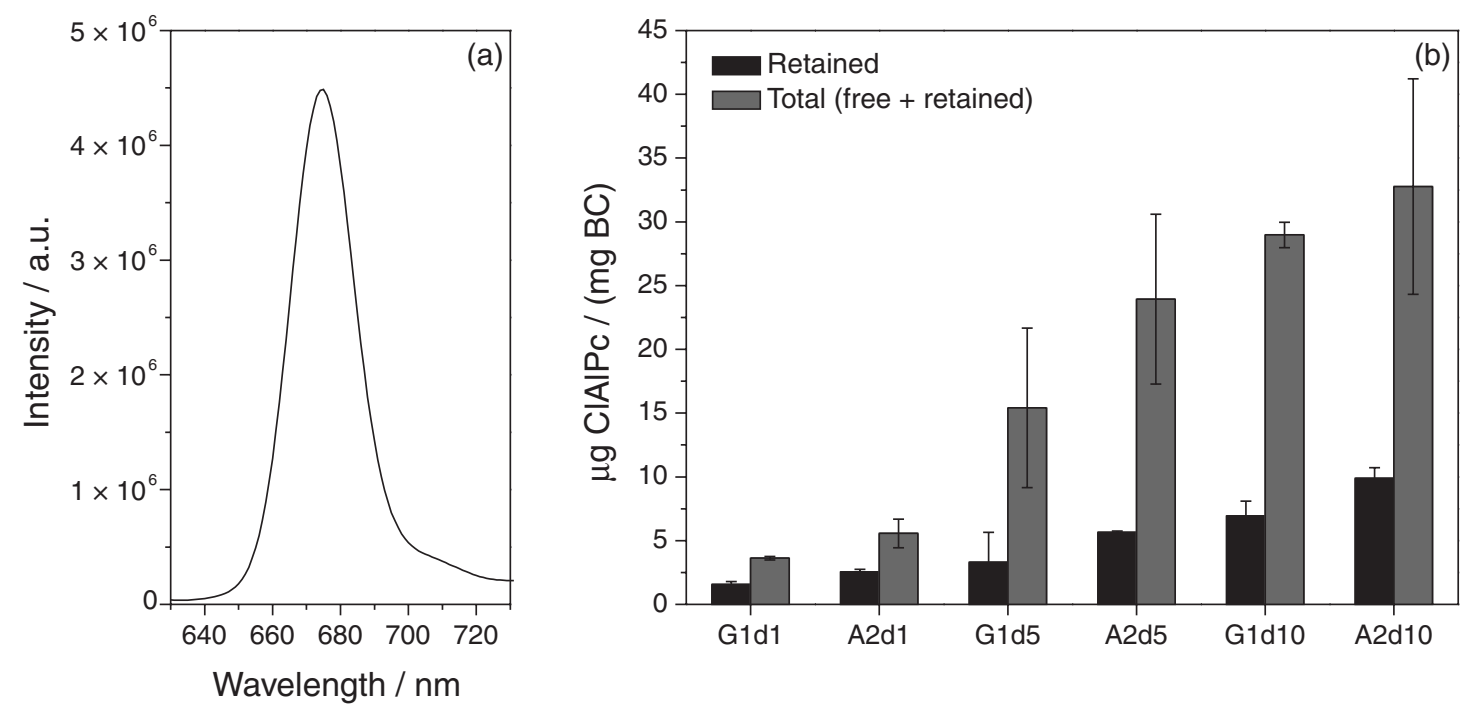

Figure 5. Chloroaluminum phthalocyanine $(\mathrm{ClAlPc})$ fluorescence emission spectrum under $615 \mathrm{~nm}$ excitation (a); and ClAlPc retained and total (free + retained) for the thinner membranes (G1d and A2d) with different theoretical concentrations of 1,5 and $10 \mu$ mol L $\mathrm{L}^{-1}$ (b). Retained and total values (in $\mu \mathrm{g}$ ClAlPc per mg BC) for the samples are, respectively: G1d1 (1.55 and 3.62), A2d1 (2.54 and 5.56), G1d5 (3.30 and 15.42), A2d5 (5.66 and 23.93), G1d10 (6.94 and 28.97), and A2d10 (9.88 and 32.76). 
cellulose matrix) showed no detectable amount of ClAlPc by fluorometry technique in the receiver solution until the period of $12 \mathrm{~h}$. The absence of ClAlPc in the receiving solution may be considered positive for topical application of the photosensitizer, because it prevents its systemic absorption, which may cause a generalized photosensitization on the patient. ${ }^{41,42}$ Stratum corneum is an efficient barrier from the external environment, controlling the flux of endogenous components outside and inside, acting as a first layer of skin with a highest lipophilic potential. ${ }^{42}$ The effective tissue penetration is constantly associated with direct interaction between drugs and SC. For cutaneous diseases is indispensable a higher $\mathrm{SC}$ penetration and adequate bioaccumulation for efficient therapies and biological response. ${ }^{41}$

In our work, the profile of cutaneous retention in $\mathrm{SC}$ and skin-deep layers (epidermis + dermis = E + D) was carried out. Samples were applied topically under biomimetic conditions in a skin animal model. After hours of administration, the apparatus were dismounted and the skin treated as described in Experimental section. Tape-stripping protocols and tissue homogenization allowed determining the amount of ClAlPc penetrated and retained in skin layers. The retention profiles are shown in Figure 6 and the results are summarized in Table 3. The ClAlPc retained in the skin layers (SC and $\mathrm{E}+\mathrm{D}$ ) was quantified after $12 \mathrm{~h}$ of testing. The retention profiles of the samples A2d1 and G1d1 are illustrated in Figure 6a. ClAlPc concentrations were present in the SC $0.492 \pm 0.037 \mu \mathrm{g} \mathrm{cm}^{-2}$ and $0.524 \pm 0.032 \mu \mathrm{g} \mathrm{cm}^{-2}$ and in the $\mathrm{E}+\mathrm{D} 0.408 \pm 0.047 \mu \mathrm{g} \mathrm{cm}^{-2}$ and $0.459 \pm 0.079 \mu \mathrm{g} \mathrm{cm}^{-2}$ to the membranes $A 2 \mathrm{~d} 1$ and $\mathrm{G} 1 \mathrm{~d} 1$, respectively. The statistical analysis (ANOVA) confirmed that there is no significant difference $(p>0.05)$ between the retention

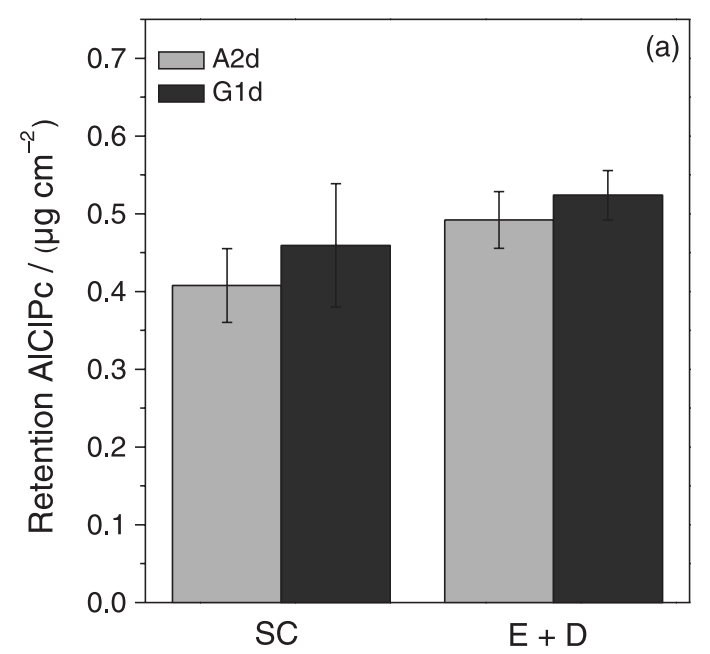

profiles of the two membranes studied in both skin layers analyzed (SC and E $+\mathrm{D}$ ). The study of ClAlPc retention in the skin layers as a function of time was conducted for the sample G1d1 for 6, 12 and $24 \mathrm{~h}$ (Figure 6b). The tests showed no ClAlPc in the receiver solution until the $24 \mathrm{~h}$ test. The retention profiles are shown in Figure $6 \mathrm{~b}$. ClAlPc concentrations detected in the SC for the different test times are: $6 \mathrm{~h}, 0.495 \pm 0.035 \mu \mathrm{g} \mathrm{cm}^{-2} ; 12 \mathrm{~h}$, $0.524 \pm 0.032 \mu \mathrm{g} \mathrm{cm}^{-2}$; and $24 \mathrm{~h}, 0.563 \pm 0.030 \mu \mathrm{g} \mathrm{cm}^{-2}$. Statistical analysis showed that the profile of the $12 \mathrm{~h}$ test is not different from the others, i.e., there is no significant difference between 6 and $12 \mathrm{~h}$ and between 12 and $24 \mathrm{~h}$; and 6 and $24 \mathrm{~h}$ tests are different. In the $\mathrm{E}+\mathrm{D}$ were quantified: $6 \mathrm{~h}, 0.070 \pm 0.023 \mu \mathrm{g} \mathrm{cm}^{-2} ; 12 \mathrm{~h}, 0.459 \pm 0.079 \mu \mathrm{g} \mathrm{cm}^{-2}$; and $24 \mathrm{~h}, 0.190 \pm 0.036 \mu \mathrm{g} \mathrm{cm}-2(\mathrm{E}+\mathrm{D})$. Statistical analysis showed a significant difference $(p>0.05)$ between the profiles of retention in the epidermis and dermis for the three different test times studied. Large variations in the retention values for the deeper skin layers (epidermis and dermis) were observed between the tests of 6,12 and $24 \mathrm{~h}$. The use of pig's ear skin as skin model may have led to variation in experimental results due to the enormous heterogeneity that exists between ears samples from different animals, or even in different regions of the same ear. However, it should be considered that this biological variability reflects the reality and it was possible to find a characteristic retention for the system. The use of human skin as a model ${ }^{26}$ would be ideal for skin permeation/ retention studies in vitro. However, this material obtained from plastic surgery presents limitations to its use, as the low availability and the need to undergo the experiment to Research Ethics Committees. ${ }^{43-45}$ Alternatively, the animal skins, such as primate, pig, rat, guinea pig and snake, are widely used..$^{46}$ Three dimensional cultures of human cells ${ }^{47}$

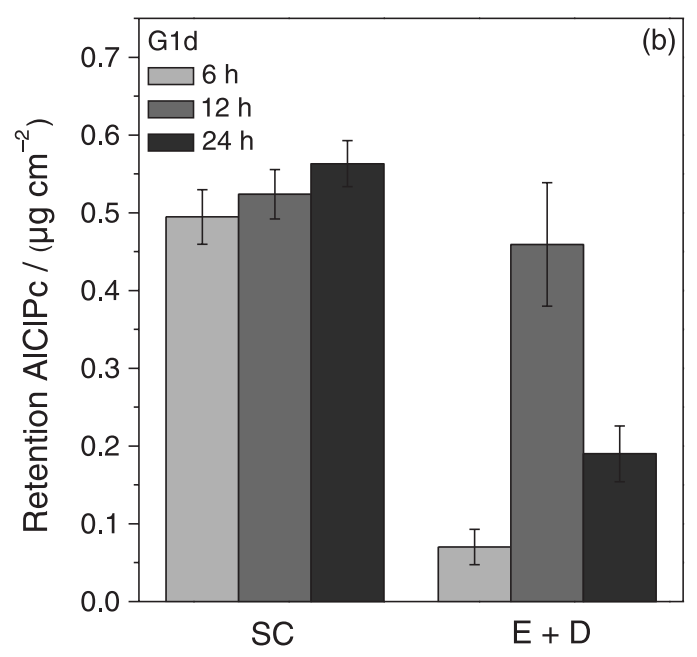

Figure 6. Penetration profiles of chloroaluminum phthalocyanine (ClAlPc) into the skin layers: epidermis + dermis (E + D) and stratum corneum (SC) for the samples A2d and G1d after $12 \mathrm{~h}$ (a); and G1d tested for 6, 12 and $24 \mathrm{~h}(\mathrm{~b})$. Results are represented as mean \pm SD $(\mathrm{n}=5)$. 
are also an option, however these materials are deficient in skin-associated epithelial structures (appendages), as pilosebaceous units, hair follicles and sweat glands. ${ }^{48}$ Synthetic membranes with defined pore sizes are also employed in assays to Franz cells to reduce inter assay variation due to biological variability of the skin tissue. ${ }^{49}$ The pig ear skin was used in this study considering the factors described above. It was also taken into account its high availability with relative ease to obtain and the low cost, once it is a by-product of the food industry. Besides being the animal model that more closely resembles histologically and biochemically to human tissue, after the primates. ${ }^{46}$

Table 3. Chloroaluminum phthalocyanine $(\mathrm{ClAlPc})$ concentrations detected in epidermis + dermis $(\mathrm{E}+\mathrm{D})$ and stratum corneum (SC) for the samples A2d and G1d after $12 \mathrm{~h}$, and for the G1d tested for 6, 12 and $24 \mathrm{~h}$

\begin{tabular}{lccc}
\hline Sample & time $/ \mathrm{h}$ & $\mathrm{SC} /\left(\mu \mathrm{g} \mathrm{cm}^{-2}\right)$ & $\mathrm{E}+\mathrm{D} /\left(\mu \mathrm{g} \mathrm{cm}^{-2}\right)$ \\
\hline A2d & 12 & $0.492 \pm 0.037$ & $0.408 \pm 0.047$ \\
\hline \multirow{2}{*}{ G1d } & 6 & $0.495 \pm 0.035$ & $0.070 \pm 0.023$ \\
& 12 & $0.524 \pm 0.032$ & $0.459 \pm 0.079$ \\
& 24 & $0.563 \pm 0.030$ & $0.190 \pm 0.036$ \\
\hline
\end{tabular}

Mean $\pm \operatorname{SD}(n=5)$.

In PDT, these phenomena related to skin permeation and retention are decisive for treatment of neoplastic cells. Before laser irradiation, it is necessary that an appropriated amount of photosensitizer penetrates the SC to a better interaction with target tissues, to accumulate in malignant cells, to promote an adequate biological response and, thus, to obtain an efficient therapy. An effective delivery system for PDT by topical administration should carry the photosensitizer beyond the stratum corneum to the malignant cells present in viable layers of the epidermis. ${ }^{41} \mathrm{~A}$ global analysis of this study permits the inference that approximately 0.5 $\mu \mathrm{g} \mathrm{cm}^{-2}$ of ClAlPc remained in the furrows of the stratum corneum and $0.3 \mu \mathrm{g} \mathrm{cm}^{-2}$ in the epidermis/dermis. The drug delivery system containing a derivative of chlorine temoporfin (the synthesis and purification of Foscan ${ }^{\circledR}$ (5,10,15,20-tetra(m-hydroxyphenyl)chlorin) was carried out by Prof PhD Philippe Maillard, coordinator of the Chimie Bioorganique's Laboratoire, Institute Curie, Orsay, France) developed by Primo et al..$^{50}$ promoted a retention of $0.5 \mu \mathrm{g} \mathrm{cm}^{-2}$ drug in the stratum corneum and $0.6 \mu \mathrm{g} \mathrm{cm}^{-2}$ in the epidermis/dermis. Thus, the results showed an interesting alternative for delivery of photosensitizers in PDT based on bacterial cellulose, a polymer well known by a wide range of features that favors its use for biomedical applications, as mentioned above. Particularly in this case, BC-ClAlPc present advantages as a drug delivery system, as the very simple approach of preparation and the absence of cytotoxicity, according to the XTT assay.

\section{Photophysical characterization}

The singlet oxygen analysis was based on the direct detection of its luminescence at $1270 \mathrm{~nm}$ to measure the luminescence-decay kinetics. Lifetimes $(\tau)$ and maximum intensities observed in the decay curves are shown in Table 4. ClAlPc solution in ethanol was also evaluated for the purpose of comparing the effect of the photosensitizer free in solution. Pheophorbide A in ethanol was adopted as a standard solution for relative calculation. The lifetime values found are very close, except for the BC-ClAlPc membrane, which showed a longer lifetime. This difference may be due to the solid form of the sample.

Table 4. Fluorescence lifetimes $(\tau)$ and maximum intensities in the decay curves for the samples

\begin{tabular}{lccc}
\hline Sample & $\tau / \mu \mathrm{s}$ & Intensity & $\begin{array}{c}\text { Increase } \\
\text { factor }\end{array}$ \\
\hline Pheophorbide A/ethanol & $0.234 \pm 0.011$ & 0.040 & - \\
ClAlPc/ethanol & $0.221 \pm 0.008$ & 0.459 & 11.5 \\
ClAlPc/BC & $0.325 \pm 0.002$ & 0.176 & 4.4 \\
\hline
\end{tabular}

BC: Bacterial cellulose; ClAlPc: chloroaluminum phthalocyanine.

Photophysical studies of BC-ClAlPc were performed for the major reactive species responsible for the destruction of tumor cells, singlet oxygen. The results shown in Table 4 are consistent with those of Siqueira-Moura et al. ${ }^{39}$ which have found similar lifetime $(0.22 \mu$ s) for ClAlPc in polymeric nanocapsules. Higher luminescence intensity was obtained for BC-ClAlPc (4.4 times) in respect to the standard solution (pheophorbide A in ethanol). This compound is a derivative bacteriological hydrochloric which produces high yield of the species being studied and is widely used as a reference in spectroscopic studies. ${ }^{36}$ Therefore, these data suggest that BC does not interfere with the production of singlet oxygen, an important condition in the PDT process.

\section{Cytotoxicity assay (XTT cell viability assay)}

Evaluation of BC-ClAlPc cytotoxicity was performed by cell viability test using Chinese hamster ovary cells (CHO-K1) because its structures and functions are common to most types of cells, i.e., the objective was to determine the basal cytotoxicity potential of BC-ClAlPc membrane. ${ }^{51}$ The cell viability is related to the absorbance 
measure. Negative control was considered $100 \%$ cell viability. Figure 7 shows the cell viability (\%) expressed as mean and standard error. Cells treated with the eluate from BC-ClAlPc membrane showed $32 \%$ of lower cell viability than negative control (without any treatment). Therefore, cell viability of the BC-ClAlPc membrane is not significantly different from NC ( $p>0.05$; Dunnett). Thus, the BC-ClAlPc membrane does not significantly affect cell viability, being non-cytotoxic.

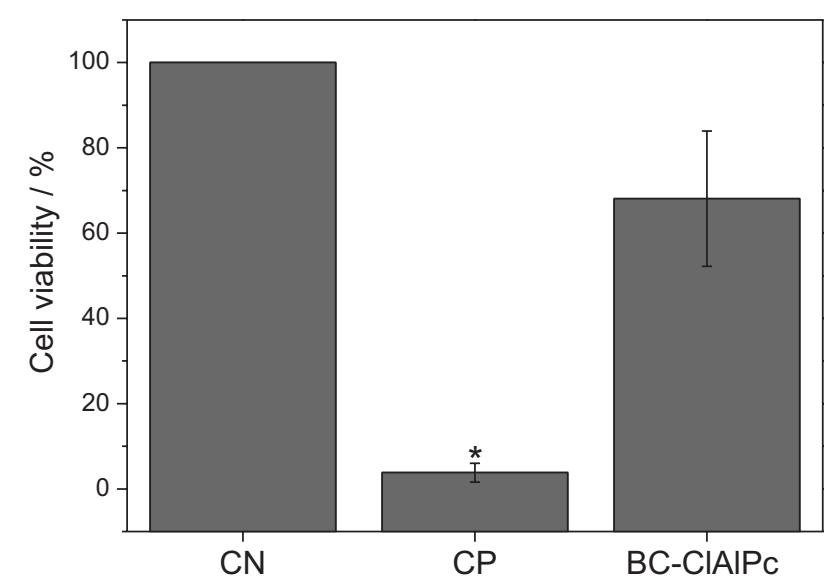

Figure 7. Cell viability obtained from XTT test for negative control (NC), positive control (PC) and bacterial cellulose (BC)-chloroaluminum phthalocyanine (ClAlPc) membrane. *Indicates statistically significant difference from the negative control. Mean $\pm \operatorname{SE}(p<0.05$, Dunnett).

For a safe use in humans, biomaterials should not present cytotoxic effects. The cytotoxicity potential of pure BC was already evaluated by Saska et al., ${ }^{52}$ which demonstrated absence of in vitro cytotoxicity effects of BC membranes. In the present study, cytotoxicity assay demonstrated that $\mathrm{BC}-\mathrm{ClAlPc}$ membrane was non-cytotoxic in CHO-K1 cells. The non-cytotoxic profile is an essential consideration when developing a material for safe use in a biomedical application. Thus, cytotoxicity assay is the first step toward ensuring the biocompatibility of a biomaterial. This fact combined with the skin permeation/retention profiles are indicators of the strong potential of BC-ClAlPc membranes as a topical drug delivery system for PDT.

\section{Conclusions}

The study showed the feasibility of using BC as a matrix for incorporation and controlled release of photosensitizers. BC membranes with different properties were obtained by varying the bacterial strains and production times. The interaction between the $\mathrm{BC}$ and ClAlPc was confirmed by FTIR spectra. The results showed that the structural properties of membranes (such as thickness, fibers amount, surface area) correlates with the drug incorporation efficiency. The permeation/retention profiles observed for BC-ClAlPc confirm the possibility of using this system in topical administration in the process of PDT. The photophysical properties of ClAlPc are not affected after its incorporation in BC membranes. Moreover, these membranes demonstrated no in vitro cytotoxicity effects, suggesting their potential for safe biological use.

\section{Acknowledgments}

This study was supported by the Brazilian agency FAPESP (process No. 2011/15759-7). Rede CON-NANOCAPES awarded a fellowship to Maristela de F. S. Peres.

\section{References}

1. Seigneuric, R.; Markey, L.; Nuyten, D. S. A.; Dubernet, C.; Evelo, C. T. A.; Finot, E.; Garrido, C; Curr. Mol. Med. 2010, 10,640 .

2. Wilson, B. C. In Photon-Based Nanoscience and Nanobiotechnology; Dubowski, J.; Tanev, S., eds.; Springer: Dordrecht, 2006, ch. 7.

3. Barreto, J. A.; O’Malley, W.; Kubeil, M.; Graham, B.; Stephan, H.; Spiccia, L.; Adv. Mater. (Weinheim, Ger.) 2011, 23, H18.

4. Dolmans, D. E.; Fukumura, D.; Jain, R. K.; Nat. Rev. Cancer 2003, 3, 380 .

5. Trauner, K. B.; Gandour-Edwards, R.; Bamberg, M.; Shortkroff, S.; Sledge, C.; Hasan, T.; Photochem. Photobiol. 1998, 67, 133.

6. Mitra, A.; Stables, G. I.; Photodiagn. Photodyn. Ther. 2006, 3, 116.

7. Jori, G.; Fabris, C.; Soncin, M.; Ferro, S.; Coppellotti, O.; Dei, D.; Fantetti, L.; Chiti, G.; Roncucci, G.; Lasers Surg. Med. 2006, 38, 468.

8. Dai, T.; Huang, Y. Y.; Hamblin, M. R.; Photodiagn. Photodyn. Ther. 2009, 6, 170.

9. Agostinis, P.; Berg, K.; Cengel, K. A.; Foster, T. H.; Girotti, A. W.; Gollnick, S. O.; Hahn, S. M.; Hamblin, M. R.; Juzeniene, A.; Kessel, D.; Korbelik, M.; Moan, J.; Mroz, P.; Nowis, D.; Piette, J.; Wilson, B. C.; Golab, J.; Ca-Cancer J. Clin. 2011, 61, 250.

10. Castano, A. P.; Demidova, T. N.; Hamblin, M. R.; Photodiagn. Photodyn. Ther. 2004, 1, 279.

11. Konan, Y. N.; Gurny, R.; Allémann, E; J. Photochem. Photobiol., B 2002, 66, 89.

12. Ernsting, M. J.; Murakami, M.; Roy, A.; Li, S. D.; J. Controlled Release 2013, 172, 782.

13. Yamagata, T.; Morishita, M.; Kavimandan, N. J.; Nakamura, K.; Fukuoka, Y.; Takayama, K.; Peppas, N. A.; J. Controlled Release 2006, 112, 343. 
14. Lancer, R.; Acc. Chem. Res. 1993, 26, 537.

15. McHugh, A. J.; J. Controlled Release 2005, 109, 211.

16. Sugibayashi, K.; Morimoto, Y.; J. Controlled Release 1994, 29 , 177.

17. Jawahar, N.; Meyyanathan, S.; Int. J. Health Allied Sci. 2012, $1,217$.

18. Rios, M.; Pharm. Technol. 2005, 29, 42.

19. Percoraro, E.; Manzani, D.; Messaddeq, Y.; Ribeiro, S. J. L. In Monomers, Polymers and Composites from Renewable Resources; Belgacem M. N.; Gandini, A., eds.; Elsevier: Amsterdam, 2008, ch. 17.

20. Czaja, W. K.; Young, D. J.; Kawecki, M.; Brown, R. M.; Biomacromolecules 2007, $8,1$.

21. Amin, M. C. I. M.; Ahmad, N.; Halib, N.; Ahmad, I.; Carbohydr. Polym. 2012, 88, 465.

22. Torres, F. G.; Commeaux, S.; Troncoso, O. P.; J. Funct. Biomater. 2012, 3, 864.

23. Huang, L.; Chen, X.; Nguyen, T. X.; Tang, H.; Zhang, L.; Yang, G.; J. Mater. Chem. B 2013, 1, 2976.

24. Bodhibukkana, C.; Srichana, T.; Kaewnopparat, S.; Tangthong, N.; Bouking, P.; Martin, G. P.; Suedee, R.; J. Controlled Release 2006, 113, 43.

25. Stoica-Guzun, A.; Stroescu, M.; Tache, F.; Zaharescu T.; Grosu, E.; Nucl. Instrum. Methods Phys. Res., Sect. B 2007, 265, 434.

26. Trovatti, E.; Freire, C. S. R.; Pinto, P. C.; Almeida, I. F.; Costa, P.; Silvestre, A. J. D.; Neto, C. P.; Rosado, C.; Int. J. Pharm. (Amsterdam, Neth.) 2012, 435, 83.

27. Almeida, I. F.; Pereira, T.; Silva, N. H.; Gomes, F. P.; Silvestre, A. J.; Freire, C. S.; Lobo, J. M. S.; Costa, P. C.; Eur. J. Pharm. Biopharm. 2014, 86, 332.

28. Padula, C.; Colombo, G.; Nicoli, S.; Catellani, P. L.; Massimo, G.; Santi, P.; J. Controlled Release 2003, 88, 277.

29. Nigoghossian, K.; Peres, M. F. S.; Primo, F. L.; Tedesco, A. C.; Pecoraro, E.; Messaddeq, Y.; Ribeiro, S. J. L.; Colloids Interface Sci. Commun. 2014, $2,6$.

30. Schmitt, F.; Lagopoulos, L.; Käuper, P.; Rossi, N.; Busso, N.; Barge, J.; Wagnières, G.; Laue, C.; Wandrey, C.; JuilleratJeanneret, L.; J. Controlled Release 2010, 144, 242.

31. Drogat, N.; Granet, R.; Le Morvan, C.; Bégaud-Grimaud, G.; Krausz, P.; Sol, V.; Bioorg. Med. Chem. Lett. 2012, 22, 3648.

32. Bionext Produtos Biotecnológicos Ltda. (Brazil). Farah, L. F. X.; Podlech, P.A.S.; Archanjo, C. R.; Coral., L. A.; US 2009/0017506.

33. Siqueira-Moura, M. P.; Primo, F. L.; Peti, A. P. F.; Tedesco, A. C.; Pharmazie 2010, 65, 9.

34. Sartorelli, P.; Andersen, H. R.; Angerer, J.; Corish, J.; Drexler, H.; Göen, T.; Griffin, P.; Hotchkiss, S. A.; Larese, F.; Montomoli, L.; Perkins, J.; Schmelz, M.; van de Sandt, J.; Williams, F.; Environ. Toxicol. Pharmacol. 2000, 8, 133.
35. Godin, B.; Touitou, E.; Adv. Drug. Delivery Rev. 2007, 59, 1152.

36. Krasnovsky Jr, A. A.; Neverov, K. V.; Egorov, S. Y.; Roeder, B.; Levald, T.; J. Photochem. Photobiol., B 1990, 5, 245.

37. Silva, W. J.; Seneviratne, J.; Parahitiyawa, N.; Rosa, E. A. R.; Samaranayake, L. P.; del Bel Cury, A. A.; Braz. Dent. J. 2008, 19, 364-369.

38. Basova, T. V.; Kiselev, V. G.; Plyashkevich, V. A.; Cheblakov, P. B.; Latteyer, F.; Peisert, H.; Chassè, T.; Chem. Phys. 2011, $380,40$.

39. Siqueira-Moura, M. P.; Primo, F. L.; Espreafico, E. M.; Tedesco, A. C.; Mater. Sci. Eng., C 2013, 33, 1744.

40. Rezaei, A.; Nasirpour, A.; Fathi, M.; Compr. Rev. Food Sci. Food Saf. 2015, 14, 269.

41. Rossetti, F. C.; Lopes, L. B.; Carollo, A. R. H.; Thomazini, J. A.; Tedesco, A. C.; Bentley, M. V. L. B.; J. Controlled Release 2011, $155,400$.

42. Shah, V. P. In Drug Permeation Enhancement - Theory and Applications; Hsieh, D. S., ed.; Marcel Dekker: New York, 1994, ch. 2.

43. Schmook, F. P.; Meingassner; J. G.; Billich, A.; Int. J. Pharm. (Amsterdam, Neth.) 2001, 215, 51.

44. Rigg, P. C.; Barry, B. W.; J. Invest. Dermatol. 1990, 94, 235.

45. Baby, A. R.; Haroutiounian Filho, C. A.; Sarruf, F. D.; Tavante Júnior, C. R.; Pinto, C. A. S. O.; Zague, V.; Arêas, E. P. G.; Kaneko, T. M.; Velasco. M. V. R.; Rev. Bras. Cienc. Farm. 2008, 44, 233.

46. Godin, B.; Touitou, E.; Adv. Drug. Delivery Rev. 2007, 59, 1152.

47. Primo, F. L.; Reis, M. B. C.; Porcionatto, M. A.; Tedesco, A. C.; Curr. Med. Chem. 2011, 18, 3376.

48. Netzlaff, F.; Lehr, C. M.; Wertz, P. W.; Schaefer, U. F.; Eur. J. Pharm. Biopharm. 2005, 60, 167.

49. Coulman, S. A.; Barrow, D.; Anstey, A.; Gateley, C.; Morrissey, A.; Wilke, N.; Allender, C.; Brain, K.; Birchall, J. C.; Curr. Drug Delivery 2006, 3, 65.

50. Primo, F. L.; Michieleto, L.; Rodrigues, M. A. M.; Macaroff, P. P.; Morais, P. C.; Lacava, Z. G. M.; Bentley, M. V. L. B.; Tedesco, A. C.; J. Magn. Magn. Mater. 2007, 311, 354.

51. Ekwall, B.; Silano, V.; Paganuzzi-Stammati, A.; Zucco, F. In Short-Term Toxicity Tests for Non-Genotoxic Effects; Bourdeau, P.; Sommers, E.; Richardson, G. M.; Hickman, J. R., eds.; Wiley: Chichester, 1990, 7, 75.

52. Saska, S.; Scarel-Caminaga, R. M.; Teixeira, L. N.; Franchi, L. P.; dos Santos, R. A.; Gaspar, A. M. M.; Oliveira, P. T.; Rosa, A. L.; Takahashi, C. S.; Messaddeq, Y.; Ribeiro, S. J. L.; Marchetto, R.; J. Mater. Sci: Mater: Med 2012, 23, 225

Submitted: December 29, 2015 Published online: March 17, 2016

FAPESP has sponsored the publication of this article. 